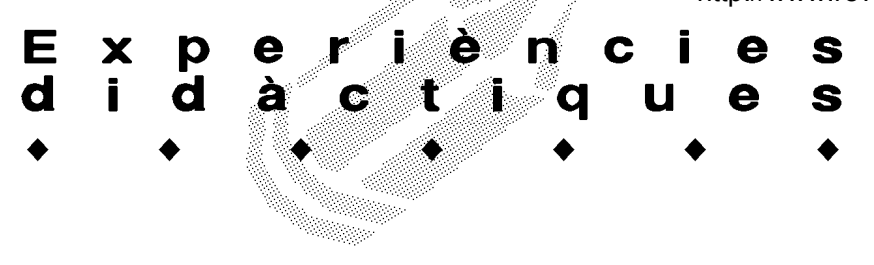

\title{
ELS OCELLS DEL PATI
}

\author{
Jesús Chivite Pérez. Mestre del CEIP "Sant Josep”. L’Hospitalet de Llobregat
}

A l'escola Sant Josep-El Pi, al barri de Sant Josep de l'Hospitalet de Llobregat, vam començar a desenvolupar un projecte al llarg del curs escolar 2001-02: Els ocells del pati, on tots els alumnes del centre van treballar i participar de formes diverses.

Al començament del curs al claustre de professors ens vam plantejar treballar aquest tema de caire monogràfic amb diferents actuacions. La idea va sorgir a partir de l'observació de l'escola i del seu entorn. Els ocells, els tenim al voltant nostre, i únicament cal parar una mica d'atenció. En diverses situacions tenim ocells per observar: quan acaba el pati menjant les restes d'esmorzars; al jardí, entre els arbustos i els arbres; a la font quan beuen; als bassals quan es banyen; als terrats cantant; a la menjadora, jugant al pati i a les classes d'educació física, volant per sobre, etc.

El projecte dels ocells del pati és un treball interdisciplinari que té com a eix vertebrador un programa informàtic fet a la mesura de les necessitats. Aquest programa -fet per l'autor- ens permet reforçar les observacions fetes al pati i facilita l'assoliment dels objectius que més avall citem. Amb aquest treball amb l'ordinador es recullen diferents activitats educatives i d'aprenentatge sobre els ocells. L'aplicació està feta amb el programa Clic 3.0, que és un entorn obert que permet adequar les feines al nivell i necessitats concretes. Els alumnes es van familiaritzant amb els ocells que poden veure al pati de l'escola, i tot jugant aprenen el seu nom en diferents idiomes, el seu cant i els identifiquen per la seva forma $i$ colors. Tots els nens de l'escola veuen, escolten $\mathrm{i}$ juguen amb els ocells del pati, que hem ficat als ordinadors. Els més grans han treballat amb trenta-un ocells diferents que teníem catalogats. Els més petits, amb deu (vegeu la taula 1). Com que és un treball globalitzador, s'ha pretès que treballin altres matèries interrelacionant-les entre si. Així doncs, s'aprenen conceptes matemàtics, de llengües, de tradicions populars, de literatura, activitats plàstiques, etc.

Des d'aquell curs 2001-02 fins a l'actualitat es fan a l'escola de forma sistemàtica i amb els alumnes de primària diferents activitats: fem les observacions al pati -sobretot a les classes d'educació física o a l'esbarjo-, fem les anotacions a les graelles dels ocells observats, posem capses niu i les mantenim, està disposada la menjadora, utilitzem el programa informàtic Els ocells del pati per aprendre i documentar-nos, fem servir els aparells d'observació: binocles, prismàtics...

Tot i que fa tres cursos l'escola va canviar d'edifici -dintre del mateix barri-, les característiques de l'entorn són semblants. Amb les observacions que estem fent durant aquests cursos estem comprovant que ens visiten gairebé els mateixos ocells. Podem veure ocells de molts tipus -tenim localitzades ara 31 espècies bastant freqüents i d'altres que no ho són tant- , que ens poden ser molt útils per aprendre aspectes molt interessants del nostre entorn i sobre la vida dels éssers vius.

\section{Objectius de l'experiència}

Ens vam plantejar uns objectius per assolir. Els més representatius són:

- Conèixer els ocells que veiem al pati de l'escola i fer observacions dels seus costums, alimentació, plomatge, nius... Identificar-los en diferents situacions: en vol, caminant, als arbres... i veure'ls com a éssers vius del nostre barri i de la ciutat.

- Recollir dades per escrit per a l'anàlisi i estudi posterior.

- Conèixer les diferents parts d'un ocell i diferenciar els diferents tipus de plomes i la seva funció. Saber observar les possibles diferències entre mascles i femelles.

- Escoltar amb atenció per identificar els cants $\mathrm{i}$ reconèixer els més característics.

- Veure actituds concretes en els ocells: època de zel, competència pels aliments que troben, delimitació del territori pel cant...

- Parlar de diferents temes relacionats amb ells com la migració, ocells en perill d'extinció, superpoblació d'ocells (per exemple, els coloms), ocells oportunistes, etc.

- Construir capses niu i menjadores.

- Respectar els ésser vius que ens envolten -plantes i animals- i l'entorn que formen part de la nostra realitat més propera.

- Comunicar als companys i professors vivències, observacions o experiències realitzades.

- Saber utilitzar de forma correcta i responsable les eines $i$ instruments que es fan servir per treballar $i$ fer observacions: ordinadors, binocles, prismàtics ...

- Saber cercar informacions de diferents fonts: 


\section{Ex}

guies, llibres, programes, internet.

- Jugar i gaudir veient i escoltant els ocells del pati dintre de l'ordinador.

- Saber veure que els ocells formen part de la cultura popular i que hi ha una representació important en els poemes, cançons, refranys, dites, textos literaris.

\section{Descripció del treball i objectius aconseguits}

Els objectius s'assoleixen amb les diferents activitats i treballs fets al llarg de tot el període.

Concretament durant el curs 2001-02, en treballar el tema dels ocells de manera monogràfica, es van fer unes activitats que els cursos posteriors ja no hem fet:

- Els tallers van tenir molt d'èxit. El de fusteria: construcció de capses niu i menjadores d'ocells amb fustes reciclades (cicle superior). El de pintura: ecosistemes diferents amb els ocells. Modelatge: van fer un mòbil de figures d'ocells fetes de fang, (cicle mitjà). Activitats de retallables, papiroflèxia, pintura, plastilina, dibuix (infantil i cicle inicial).

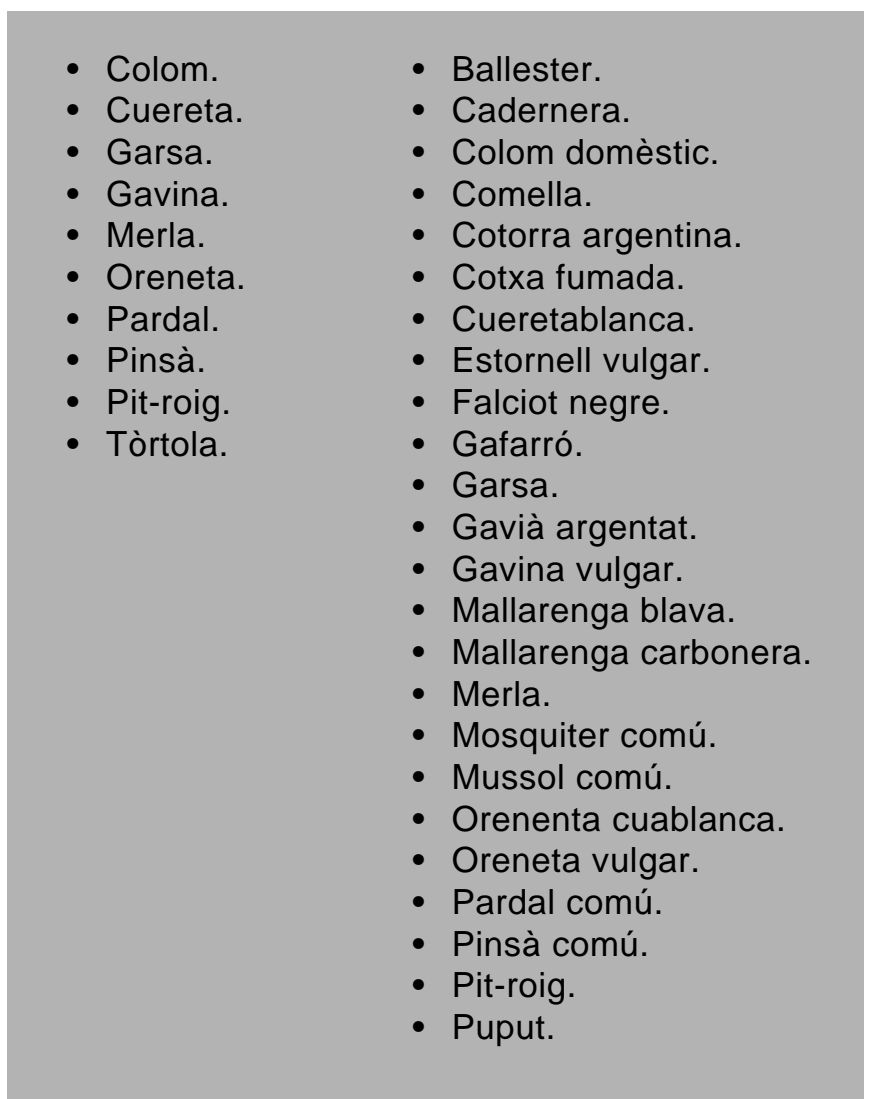

Taula 1. Llistat d'ocells amb els quals treballen els alumnes més petits (esquerra) i els més grans (dreta).
- Construcció de les seves pròpies disfresses d'ocells pels mestres de l'escola.

- Guarniment de passadissos amb murals, mòbils, capses niu, pòsters, etc.

- Presentació als pares del projecte Els ocells de pati i del llibre El rei dels ocells a les tertúlies mensuals Cafè $i$ llibres.

- Treball a les sessions de música del tema: Música i ocells. Recopilació de peces clàssiques on es tracti el tema dels ocells.

- Diferents reculls: de cançons populars sobre ocells, de contes i textos de literatura infantil, recull de dites, refranys, frases fetes, endevinalles.

- La revista escolar ESJEP va dedicar un número monogràfic al tema dels ocells, on tots els alumnes van participar amb treballs i articles.

- Per a la setmana de Sant Jordi els alumnes de cicle superior van fer uns tallers de poesia sobre el tema: Ocells i natura.

- Enlairada de globus amb un missatge, poema o escrit penjat de la corda perquè volés i volés com els ocells.

- Elaboració de llibres col-lectius sobre contes, dites i refranys, projectes específics sobre un ocell, endevinalles.

- Muntatge de l'exposició: El rei dels ocells. Entre mestres, pares i alumnes la biblioteca escolar es va transformar en un bosc on s'accedia per una cova i on els visitants podien gaudir d'una estona agradable escoltant un conte, escoltar els cants dels ocells, mirar i remirar treballs fets pels alumnes de l'escola, fullejar llibres científics i de literatura sobre el tema de les aus, mirar fotografies sobre l'experiència dels alumnes i dels ocells, veure diferents reculls de plomes, nius, reclams, observar estris d'observació com els binocles i els prismàtics. Tot això sota els arbres i els ocells, que en aquest cas eren de paper i que donaven vida a aquest bosc temporal.

Actualment continuem la tasca fent les següents activitats:

- Es fan anotacions mensuals dels ocells observats al pati mitjançant unes graelles on cada mes es fa el buidatge de la informació recollida, i així tenim els noms dels ocells, llocs, observadors, dates, gràfics d'abundància i altres anotacions d'interès...

- Amb cada resum mensual fem un gràfic-resum representatiu dels ocells vistos, on incorporem les valoracions fetes cada mes $i$ també incorporem imatges captades al mateix centre $o$ a les rodalies. Amb tots aquests resums mensuals, durant cada curs, es fa un estudi general de totes les observa- 


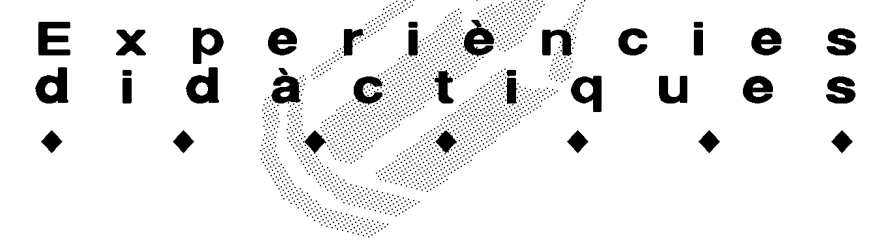

cions i les conclusions extretes sobre la feina.

- Hem fet el Kit d'observació d'ocells, compost per dos binocles, làmines d'identificació d'ocells del pati, fotografies i dibuixos plastificats de cada espècie, petites guies d'ocells i la càmera de fotos digital.

- També fem observacions periòdiques a ull nu i amb prismàtics, dels ocells que comparteixen amb nosaltres el pati i el barri.

- Es fa un recull fotogràfic dels ocells del pati i de les activitats fetes al centre sobre aquest tema.

- Pengem capses niu i mantenim la menjadora al pati de l'escola.

- Algunes de les sortides i colònies escolars que tenim programades encaixen perfectament amb aquest tema i d'altres d'interès: delta de l'Ebre (cicle superior), Montseny (cicle inicial), granja escola (cicle mitjà), parc de Collserola (infantil).

- Recollida de materials: plomes, nius, closques d'ou, etc. que després classifiquem i guardem al laboratori.

- Programes informàtics d'interès per treballar concretament els ocells o d'altres més generals per tenir una visió global del medi natural.

- Recull d'aplicacions d'internet i adreces sobre el tema.

- Bibliografia específica i general per al laboratori i biblioteca escolar sobre temes i qüestions de ciència relacionats.

\section{Valoració i conclusions}

El que va ser i és important d'aquest treball és que desperta la curiositat per observar i aprendre fora de les aules i poder després fer les valoracions i estudis oportuns amb els estris adients.

Les activitats que engloba agraden molt als alumnes i desperten la seva curiositat envers qüestions científiques i de la vida real, ajudant-los a observar el seu entorn.

Totes les feines estan integrades dintre del funcionament normal de les matèries curriculars i activitats habituals que es fan a l'escola. Així, quan cal fer una referència al tema, no cal allunyar-se gaire per veure, sinó anar a la realitat més propera a nosaltres i que també cal conèixer: respectar i observar per comprendre que també a les ciutats i els pobles hi ha d'haver un equilibri entre els éssers vius que compartim l'espai.

La possibilitat d'utilitzar diferents recursos per observar, estudiar, analitzar (aparells d'observació, estratègies de treball i ús de les TIC) ha permès treballar conceptes que potser ja es treballaven habitualment, però donant-los un enfocament diferent des de l'obser- vació d'ocells.

Les observacions es fan sobretot a les classes d'educació física: ens sobrevola un enorme gavià argentat, es baralla un grup de pardals als pollancres, vénen els coloms a beure a la font, la cotxa fumada fa saltirons a la pista, sentim el cant del pit-roig al jardí, les cueretes sembla que segueixen les ratlles pintades al pati, les cotorres passen sobre nosaltres amb tant guirigall com sempre, la tórtora aprofita un fanal d'observatori, les gavines vulgars es disputen un tros de xoriço caigut d'un entrepà... i així podríem seguir explicant diferents situacions en les quals els nens veuen que al seu pati d'esbarjo poden aprofitar i mirar amb atenció allò que els professors i els llibres de classe expliquen amb textos i fotos.

Com a conclusió podem dir que els resultats han estat molt bons, sobretot pel que fa a la resposta dels alumnes. Se'ls va començar a donar alguna pauta d'observació, estris de treball, plantejament d'incògnites i el seu interès i curiositat va fer la resta.

S'han adonat, doncs, que allò que diuen els llibres és veritat i que quan hem d'observar un ecosistema no cal anar gaire lluny per veure vida: al pati n'hi ha molta,

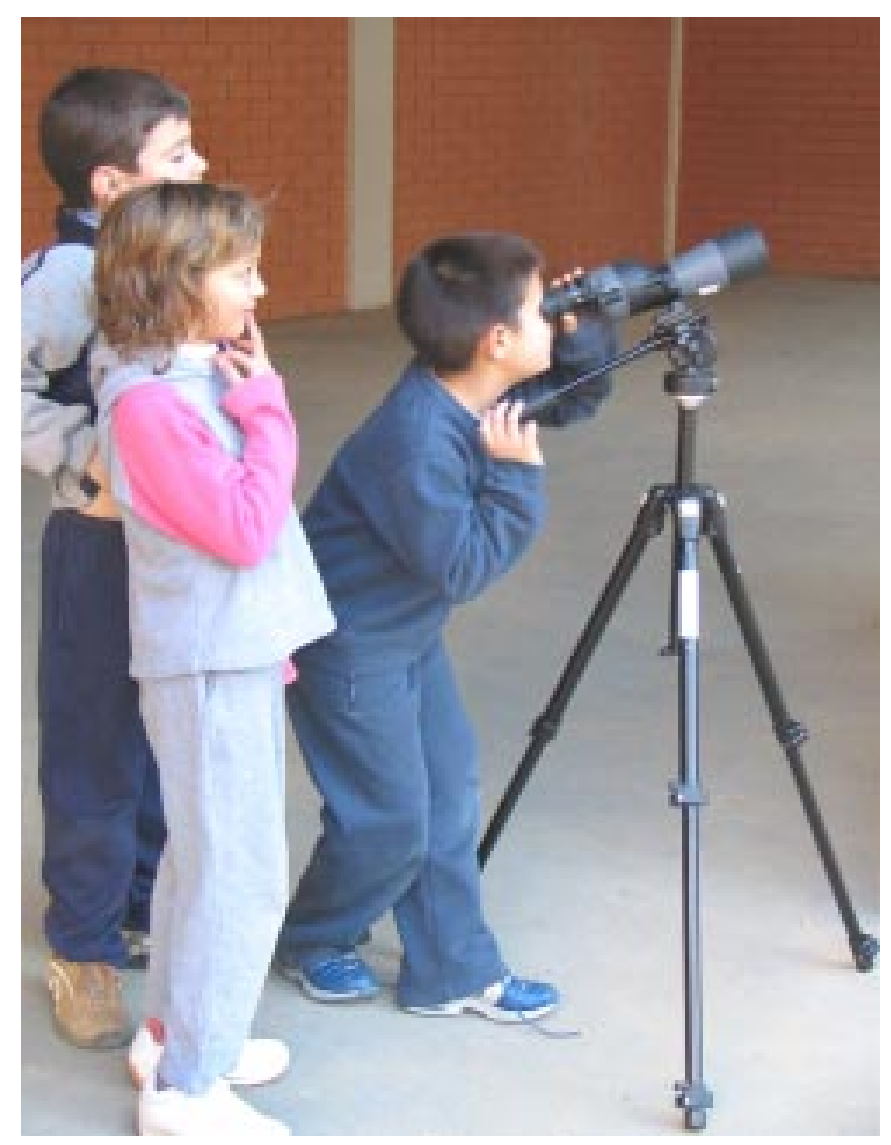






el que cal és saber-la mirar i saber veure aquestes interrelacions que hi ha entre animals que depenen uns dels altres i que es mantenen en un equilibri delicat $\mathrm{i}$ fràgil, i que s'ha de vetllar perquè no es destrueixi.

Han après tot jugant i mirant. I després han sabut extrapolar els aprenentatges i han vingut voluntàriament amb observacions, materials, notícies, llibres, nius, plomes, ous, fotos, etc. sobre ocells del pati i de fora. I ens hem trobat a l'escola amb una col-lecció de materials sobre el tema molt rica i vàlida, que restarà com a fons documental del mateix centre i que, el que és més important, s'ha fet entre tots.

Les paraules dels nens en les seves reflexions ens mostren com ha estat d'agraït aquest tema per a ells. Aquí tenim una petita representació del parer d'alguns alumnes:

- "Això de posar les capses niu i les menjadores m'ha agradat, perquè així podíem fotografiar els ocells mentre menjaven i també perquè es refugiaven".

- "Els ocells han pogut tenir casa i menjar sense moure un dit".

- "Vam fer un taller anomenat construcció de nius i semblava que fer les capses niu era molt difícil, però una vegada agafes la marxa eren molt fàcils."

- "Hem conegut molts ocells, d'alguns no en teníem ni idea; a més hem fet un treball d'informàtica sobre els ocells del pati”.

" "Amb els prismàtics hem observat els ocells des de molt a prop".

- "He après molts noms d'ocells. Quan jugàvem també estàvem aprenent".

- "Amb el treball dels ocells del pati hem après molt, hem après a reconèixer els ocells, hem escoltat els seus cants, hem vist moltes plomes diferents, hem observat els ocells amb prismàtics".

- "Jo crec que ha sigut una bona idea fer capses niu i les menjadores, perquè així els ocells poden menjar coses bones".

- "El treball dels ocells del pati m'ha agradat molt perquè hem après molt. L'exposició que hem fet $a$ la biblioteca ha sigut molt bonica perquè en el treball dels ocells tothom del col-legi hi ha contribuït una mica".

- "Aquest curs he après molt gràcies al Jesús i altres professors. Hem après a identificar els ocells del pati. Els noms dels ocells en anglès i el nom científic".

- "Abans, quan passava un ocell, ni ens n'adonàvem; però ara, quan veiem un ocell, pensem com es deu dir, si no ho sabem".

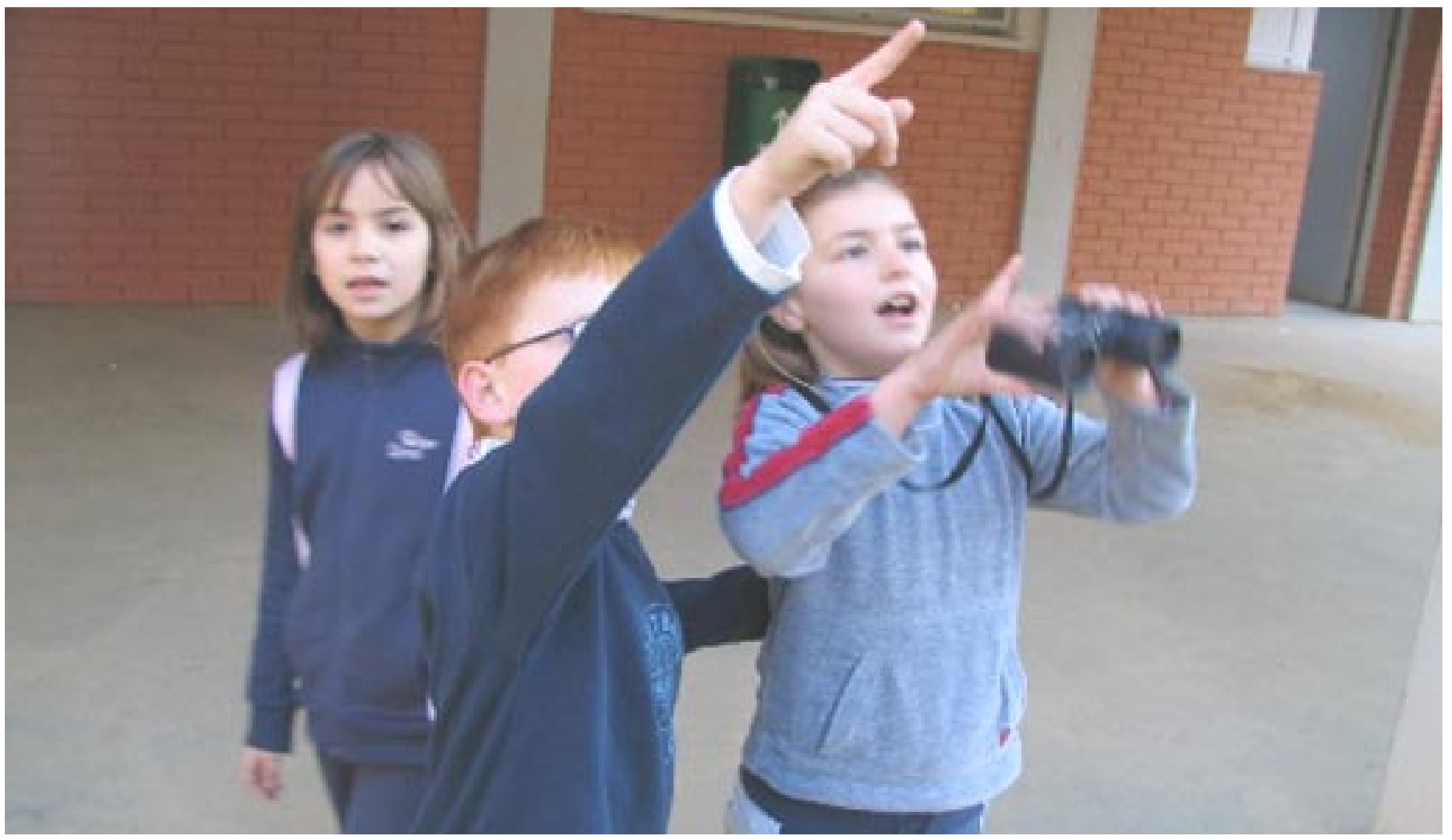




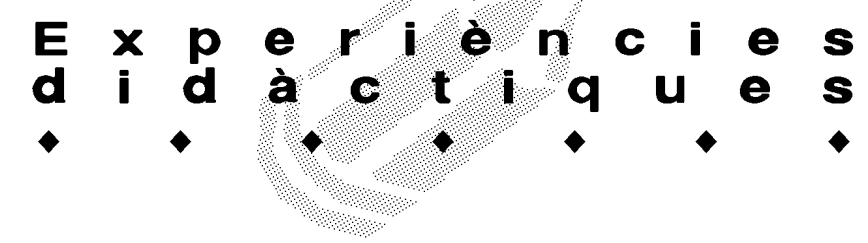

\section{Annex}

Els ocells del pati és un treball interdisciplinari que es fa a partir d'una aplicació informàtica feta amb el programa Clic 3.0 i que després es treballa en altres matèries fora de l'aula d'informàtica.



El programa està fet en tres versions diferents: primària en català, primària en castellà $i \mathrm{a}$ infantil $\mathrm{i}$ cicle inicial en català (aquesta última no és encara a Internet). Són activitats multimèdia on hi ha imatge, so i es demana molta interacció amb l'alumne.

La versió catalana per a primària -preferiblement per als cicles mitjà i superior- té 123 activitats agrupades en 8 paquets clic:

- Identifiquem els ocells: Informació sobre el nom i el cant dels ocells. Identificacions, relacions i associacions entre l'ocell i el seu nom i cant.

- Coneixem millor els ocells: Identificació en làmines, parts de l'ocell, dimorfisme sexual, les plomes: parts i tipus, el niu, capsa-niu, la migració, puzzles diversos.

- Sopes d'ocells: Localització dels noms dels ocells en diferents sopes en ordre de dificultat, amb el reforç de la imatge i el cant.

- Refranys, expressions i maneres de dir: Activitats de llengua basades en refranys, expressions, maneres de dir, puzzles d'ordenar refranys.

- Juguem amb els ocells: Jocs de diferències, comptar ocells, identificar siluetes, mots encreuats, ocell de paper.

- Juguem amb les paraules: Activitats de llengua i literatura amb cançons, poemes, escriptura correcta del nom dels ocells.

- Fem puzzles: Puzzles de diferents tipus.

- Guia i cants dels ocells: Informació sobre ocells, consells d'ús de la guia, terminologia de les parts d'un ocell, ús de prismàtics, 31 fitxes de descripció dels ocells del pati amb la imatge i el seu cant.
La versió castellana té 137 activitats, també agrupades en 8 paquets similars als de l'anterior versió.

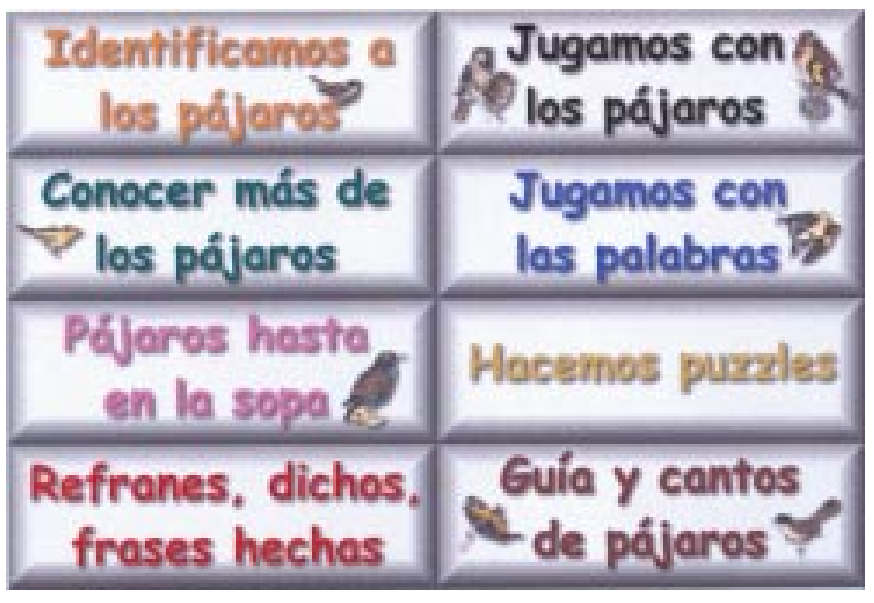

$\mathrm{Hi}$ ha les diferències pròpies de la llengua, sobretot al paquet "Refranes, dichos y frases hechas".

La versió d'infantil i cicle inicial treballa amb els deu ocells més comuns. Té 70 activitats agrupades en 6 paquets.

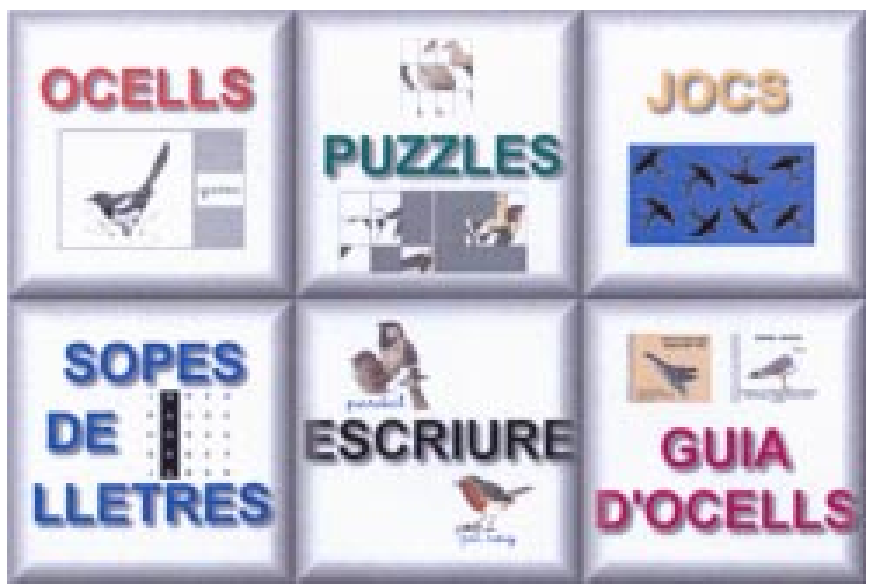

Tot aquest material informàtic també el tenim en suport paper en llibres $i$ làmines que ens ajuden a treballar-lo a la classe.

Adreça web de l'àrea Clic on podem trobar dues de les tres activitats mencionades:

http://clic.xtec.net/db/act_ca.jsp?id=1097 